\title{
Human shoulder tendon biopsy samples in organ culture produce procollagenase and tissue inhibitor of metalloproteinases
}

\author{
S Dalton, T E Cawston, G P Riley, I J L Bayley, B L Hazleman
}

North Sydney

Orthopaedic and Sports Medicine Centre, Crow's Nest, Sydney, NSW 2065, Australia $S$ Dalton

Rheumatology Research Unit, Addenbrooke's Hospital,

Cambridge,

United Kingdom

T E Cawston

G P Riley

B L Hazleman

Royal National

Orthopaedic Hospital

Stanmore, Middlesex,

United Kingdom

I J L Bayley

Correspondence to:

Dr Cawston,

Rheumatology Research Unit, Addenbrooke's Hospital, Hills Road,

Cambridge CB2 2QQ,

United Kingdom.

Accepted for publication

6 March 1995

\begin{abstract}
Objective-To investigate the production of the matrix metalloproteinase (MMP), collagenase (MMP-1), and its natural inhibitor, the tissue inhibitor of metalloproteinases (TIMP) by diseased human tendon samples in organ culture.

Methods-Portions of tendons were excised from the shoulders of patients undergoing shoulder surgery, classified as either proximal to the lesion (abnormal) or distal to the lesion (normal) according to their macroscopic appearance at surgery, and placed in organ culture for periods of up to 28 days. The release of collagenase and TIMP activity in the conditioned culture medium was measured.

Results-Procollagenase and TIMP were both produced by all the tendon samples for an extended period of time. The levels of enzyme and inhibitor varied between patients, but in most of them TIMP levels were greater than collagenase levels. In one sample of calcified tendon, procollagenase levels were greater than those of TIMP. The mean level of collagenase produced by tendon proximal to the lesion and tendon distal to the lesion were not significantly different $(95 \cdot 2$ (SD 106.8) $\mathrm{U} / \mathrm{g}$ and $34.0(45.3) \mathrm{U} / \mathrm{g}$, respectively), while the corresponding figures for TIMP were $109.7 \quad(62.3) \quad \mathrm{U} / \mathrm{g}$ and $53.0 \quad(27.9) \quad \mathrm{U} / \mathrm{g}$ $(p=<0 \cdot 05)$, although there was considerable variation in some samples. Western blotting and collagen fragment analysis confirmed that the collagenolytic activity detected was attributable to the metalloproteinase fibroblast collagenase (MMP-1). Conclusions-Tendon tissue can actively secrete procollagenase, an enzyme that, once activated, is capable of remodelling collagen, the major connective tissue component of tendon. Collagenase is produced even in unstimulated cultures, although the concentrations of TIMP are usually greater than that of collagenase in most samples. Some activation of collagenase appeared to have occurred. These results indicate that tendon tissue cells are capable of producing a remodelling response, even in end stage tendon disease.
\end{abstract}

(Ann Rheum Dis 1995; 54: 571-577)
Chronic tendon lesions are extremely common, but the underlying pathology and predisposing factors are poorly understood. These lesions usually occur in middle age without any single traumatic episode and are thought to be the result of overuse and repetitive microtrauma, which persistently reduce the ability of the tendon to repair itself. Consequently, investigations of the repair activities and functions of aging human tendon cells (tenocytes) are of central importance in understanding the pathology of such lesions.

Tendons allow muscles to initiate or limit movement-their role is relatively passive and their metabolism low. They are composed predominantly of type I collagen fibres, between which are found low numbers of elongated fibroblasts, the tenocytes, that are responsible for the maintenance of the health of the tissue. ${ }^{1}$

Tendon repair after trauma, as in other connective tissues, involves a sequence of overlapping phases of cellular activity characteristic of wound healing. ${ }^{2}$ An inflammatory phase associated with oedema and cellular infiltration is followed by a fibroproliferative phase of synthetic activity by tissue fibroblasts, followed by a remodelling phase in which the scar tissue is replaced by normal tissue. However, the precise mechanisms and cell types involved in tendon repair are unclear and it is not known whether the repaired (scar) tissue can ever return to the structural and functional integrity of the original tendon. Studies of equine tendons, for example, have shown the persistence of an abnormal collagen composition (up to $30 \%$ type III collagen) for many months and even years after acute tendon injury. $^{3}$

Early studies of tendon healing suggested that tendon repair was dependent on the ingrowth of fibroblasts from surrounding tissues and that tendon fibroblasts were not involved. ${ }^{4}$ Subsequently, organ cultures of animal tendon segments demonstrated that tendon cells can respond to injury, with increased cell growth and new collagen synthesis, supporting the concept of intrinsic flexor tendon healing. ${ }^{5-7}$ These and other studies have shown that the most active cells in the repair process are derived from the epitenon, which surrounds the tendon fibre bundles-these cells proliferate and migrate to the sites of tendon injury. ${ }^{8}$ However, an increased synthesis of 
collagen is found both in the epitenon and in deep, internal tendon fibroblasts ${ }^{9}$ and there is increased proteoglycan turnover, protein synthesis, and collagen deposition and turnover, indicating extensive metabolic activity throughout the tendon. ${ }^{10}$

The majority of these studies, however, have been conducted on animal tendons after transsection and their relevance to overuse injury of aging human tendons is questionable. Investigations of human tendons are limited by a lack of human tissue, as tendon lesions are rarely biopsied. We have recently obtained access to a unique resource of both normal and abnormal human tendon material, obtained, for example, during open shoulder surgery to repair chronic tendon lesions. The rotator cuff complex in the shoulder consists of four tendons (the supraspinatus, subscapularis, infraspinatus and teres minor) which together envelop the head of humerus and stabilise the glenohumeral joint. Supraspinatus tendons, in particular, are often affected by chronic tendon fibre failure, a poorly characterised tendon lesion associated with aging, hypovascularity, repetitive microtrauma, overhead activities and 'impingement' against the overlying acromium.

We have shown that rotator cuff tendons affected by chronic tendon disease have an altered matrix composition, including a reduced total collagen concentration and a significantly increased proportion of type III collagen. ${ }^{11} 12$ Changes in collagen composition were also detected in $17 \%(10 / 60)$ of macroscopically normal supraspinatus tendons before tendon rupture, suggesting an altered pattern of collagen synthesis and turnover, possibly as a result of a defective or slow repair response in the aging tissue, which may predispose to chronic disease and tendon rupture.

The remodelling and repair of collagen in connective tissues is a poorly understood process which involves both new collagen synthesis and the limited destruction (turnover) of collagen fibres, to weave new collagen into the existing tendon fibre structure. ${ }^{13}$ The matrix metalloproteinases (MMPs) are a family of potent enzymes ${ }^{14}$ that, once activated, can completely degrade all components of con-

Details of patients and samples of tendon obtained for analysis

\begin{tabular}{|c|c|c|c|c|}
\hline Patient & Sex & Age (yr) & Tendon & Region and classification \\
\hline $\begin{array}{l}1 \\
2 \\
3 \mathrm{~A}+\mathrm{B}\end{array}$ & $\begin{array}{l}\mathbf{M} \\
\mathbf{M} \\
\mathbf{F}\end{array}$ & $\begin{array}{l}21 \\
58 \\
70\end{array}$ & $\begin{array}{l}\text { SSC } \\
\text { SST } \\
\text { SST }\end{array}$ & $\begin{array}{l}\text { Recurrent dislocation-normal } \\
\text { Region of degenerate tear-abnormal } \\
\text { A = Region of degenerate tear-abnormal } \\
\text { B = Distant from tear-normal }\end{array}$ \\
\hline $\begin{array}{l}4 \\
5 \\
6 \\
7 \mathrm{~A}+\mathrm{B}\end{array}$ & $\begin{array}{l}\mathbf{M} \\
\mathbf{M} \\
\mathbf{F} \\
\mathbf{M}\end{array}$ & $\begin{array}{l}19 \\
25 \\
22 \\
60\end{array}$ & $\begin{array}{l}\text { SST } \\
\text { SST } \\
\text { SSC } \\
\text { SSC }\end{array}$ & $\begin{array}{l}\text { Rupture-abnormal } \\
\text { Rupture-abnormal } \\
\text { Recurrent dislocation (scarred)-abnorma } \\
\text { A = Region of degenerate tear-abnormal } \\
\text { B Distant from tear-normal }\end{array}$ \\
\hline $\begin{array}{l}8 \\
9 \\
10 \\
11 \\
12 \\
13 \\
14 \\
15 \text { A }+ \text { B } \\
16 \\
17 \\
18\end{array}$ & $\begin{array}{l}\mathbf{M} \\
\mathbf{M} \\
\mathbf{F} \\
\mathbf{F} \\
\mathbf{M} \\
\mathbf{M} \\
\mathbf{M} \\
\mathbf{F} \\
\mathbf{M} \\
\mathbf{M}\end{array}$ & $\begin{array}{l}36 \\
56 \\
26 \\
68 \\
43 \\
25 \\
38 \\
37 \\
36 \\
36 \\
50\end{array}$ & $\begin{array}{l}\text { SSC } \\
\text { SST } \\
\text { SST } \\
\text { SSC } \\
\text { SST } \\
\text { SSC } \\
\text { SST } \\
\text { SST } \\
\text { SST } \\
\text { SSC } \\
\text { SST }\end{array}$ & $\begin{array}{l}\text { Recurrent dislocation-normal } \\
\text { Previous tear and repair-abnormal } \\
\text { Recurrent dislocation-normal } \\
\text { RAVTSR-abnormal } \\
\text { Tendinitis (inflamed tendon)-abnormal } \\
\text { Instability-normal } \\
\text { ACJ decompression-normal } \\
\text { ACJ degeneration-both A + B normal } \\
\text { ACJ decompression-normal } \\
\text { Humeral fracture-normal } \\
\text { Calcific tendinitis-abnormal }\end{array}$ \\
\hline
\end{tabular}

$\mathrm{ACJ}=$ Acromioclavicular joint; $\mathrm{RA}=$ rheumatoid arthritis; SSC = subscapularis; SST = supraspinatus; TSR = total shoulder replacement. nective tissue. The best known of these is collagenase, an enzyme first described in the resorbing tadpole tail, ${ }^{15}$ but subsequently shown to be synthesised by any connective tissue fibroblast. In addition, to control the local activity of activated proteinases, the same cells produce a specific proteinaceous inhibitor (tissue inhibitor of metalloproteinases (TIMP)) that binds to the enzyme and prevents degradation. ${ }^{16}$ These enzymes and their inhibitors are believed to be involved in a large variety of both physiological and pathological conditions in which connective tissue turnover occurs. ${ }^{17}$

In this study we have examined aging human tendons removed from patients with chronic tendon disease in order to determine whether the turnover of collagen in these tendons is related to the synthesis of collagenase and if this activity is limited by the production of TIMP.

\section{Materials and methods}

\section{PATIENT SAMPLES}

Eighteen patients presented for surgery with a variety of conditions requiring shoulder surgery (table). Twenty one biopsy specimens, including eight subscapularis and 13 supraspinatus tendons, were collected. Eleven specimens were obtained either from sites distant from the tendon lesion (for example a degenerative tear), or from patients with recurrent dislocations or shoulder instability. These specimens had a macroscopically normal appearance and were described as 'normal'. Ten specimens were taken from sites adjacent to the tendon lesion, had a macroscopically abnormal appearance, and were described as 'abnormal': four specimens came from acute tendon ruptures, four from cases of chronic degenerative tears, one from calcifying tendinitis, and one from a patient with rheumatoid arthritis requiring total shoulder replacement. Three patients had duplicate specimens taken.

\section{TISSUE CULTURE}

Tendon tissue obtained from patients undergoing shoulder surgery was removed and transported to the laboratory in holding medium (Hanks's balanced salt solution buffered with $20 \mathrm{mmol} / \mathrm{h} N$-2-hydroxyethylpiperazine- $N$ '-2ethane sulphonic acid (HEPES) (Gibco, Paisley, Scotland). Tendon pieces were dissected free of any muscle or fat, blotted onto filter paper, weighed and carefully cut into strips $1-3 \mathrm{~mm}$ thick and up to $5 \mathrm{~mm}$ long, and placed in $2 \mathrm{ml}$ of Dulbecco's modification of Eagle's medium (DMEM) supplemented with $20 \mathrm{mmol} / 1$ HEPES, $1 \%$ acid treated fetal calf serum (ATFCS) and antibiotics (Gibco) in a 12 well plate NUNC (Gibco). Triplicate samples of each tendon were cultured at $37^{\circ} \mathrm{C}$ in a humidified atmosphere. The tendon was left overnight then the medium was removed (day 0 ) and its volume measured and replenished with a further aliquot of medium. This procedure was repeated on days $3,7,10$, 
14, and, in some cases, 18, 21, and 28. All media were removed, made $0.02 \%$ with respect to sodium azide and stored at $-20^{\circ} \mathrm{C}$ until required for assay.

PROCOLLAGENASE AND TIMP ASSAYS

Procollagenase was activated by the addition of 4-aminophenylmercuric acetate (APMA) $0.7 \mathrm{mmol} / \mathrm{l}$ to the supernatants and determined by the diffuse fibril assay ${ }^{18}$ using ${ }^{14} \mathrm{C}$-labelled calf skin collagen as substrate. Inhibitor was measured by assaying a known amount of active collagenase in the presence of the culture supernates. Levels of TIMP and procollagenase were expressed as units of activity per gram of tendon tissue: 1 unit of collagenase degrades $1 \mu \mathrm{g}$ of collagen per minute at $37^{\circ} \mathrm{C}$; 1 unit of TIMP inhibits 2 units of collagenase by $50 \%$.

\section{DETECTION OF COLLAGENASE AND TIMP BY} WESTERN BLOTTING

Selected culture supernatants containing both collagenase and TIMP were concentrated five to 10-fold using Amicon centricon concentrators with an $M_{\mathrm{r}}-10000$ molecular weight membrane. The concentrated medium was separated by sodium dodecylsulphatepolyacrylamide gel electrophoresis (SDSPAGE) and the separated proteins transferred to nitrocellulose and then probed with rabbit anti-human collagenase $\mathrm{IgG}^{19}$ or rabbit antihuman TIMP IgG, ${ }^{20}$ followed by horseradish peroxidase-conjugated swine antirabbit IgG. Colour was developed using metal enhanced diaminobenzidine tetrahydrochloride (DAB) (Pierce, UK) as substrate.
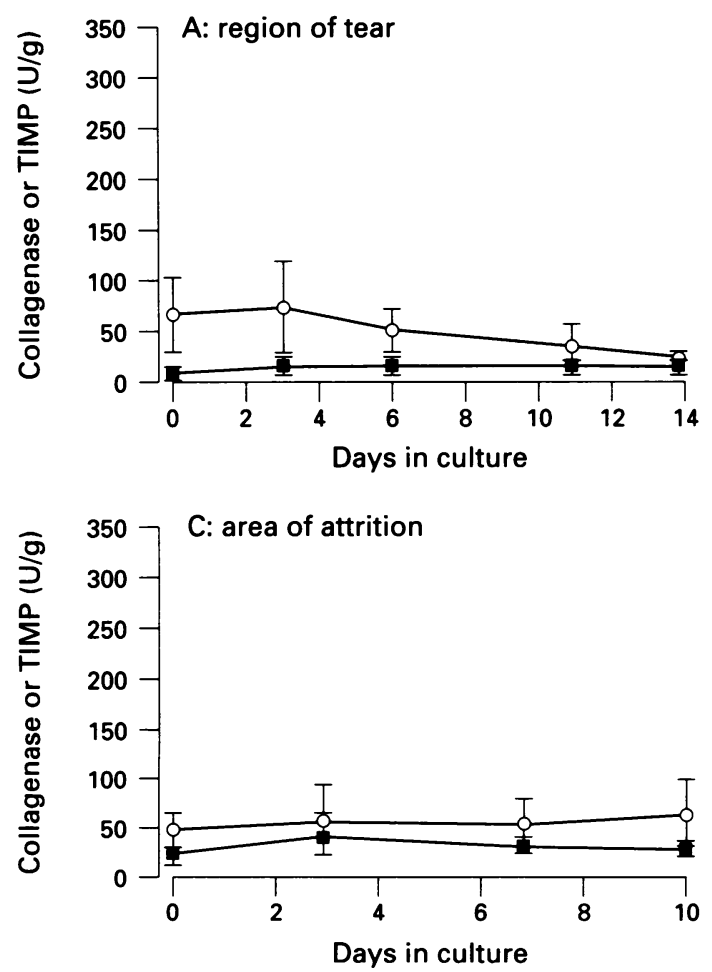

CONFIRMATION OF ORIGIN OF COLLAGENOLYTIC ACTIVITY IN MEDIUM

Concentrated medium containing high levels of collagenase (obtained from patient 15 on day 6) was treated at room temperature for 15 minutes with $50 \mu \mathrm{g} / \mathrm{ml}$ trypsin and the activation stopped by the addition of a fivefold excess of soyabean trypsin inhibitor. The activated medium was added to an equal volume of a $1 \mathrm{mg} / \mathrm{ml}$ collagen solution in $100 \mathrm{mmol} / \mathrm{h}$ Tris/hydrochloric acid buffer $\mathrm{pH} 7.6$ containing $10 \mathrm{mmol} / \mathrm{l}$ calcium chloride and $1 \mathrm{~mol} / \mathrm{l}$ glucose alone or in the presence of $5 \mathrm{mmol} / \mathrm{l}$ 1.10-phenanthroline. After incubation for 24 hours at room temperature, the samples were separated on a $7.5 \%$ SDS-PAGE gel and stained with Coomassie Brilliant Blue.

\section{OTHER MATERIALS}

All other chemicals or biochemicals were obtained from Fisons, Loughborough, UK, or have been described previously. ${ }^{21}$

\section{STATISTICAL ANALYSIS}

Statistical significance of the difference between sample means was tested by Student's $t$ test.

\section{Results}

Triplicate samples of tendon tissue was cultured for at least 14 days and in some instances up to 28 days. Each tendon sample was weighed and the wet weights of the tendon samples varied between 15 and $213.5 \mathrm{mg}$ (mean 55.9 (SD 38.9) $\mathrm{mg}$ ).

Figure 1 illustrates representative data obtained for the majority of tendon specimens.
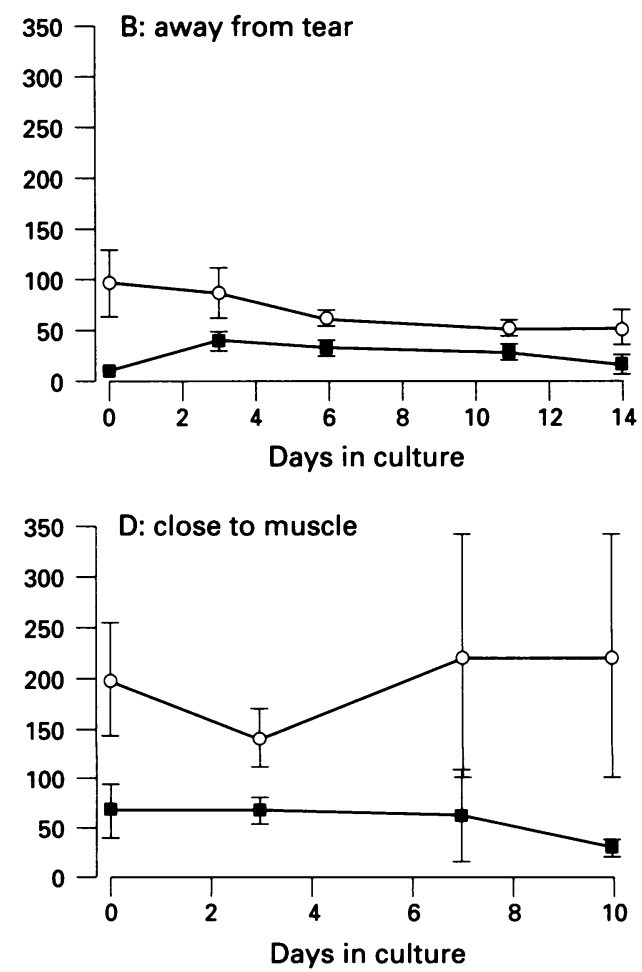

Figure 1 Levels of collagenase ( $\mathrm{B}$ ) and tissue inhibitor of metalloproteinases (TIMP) (O) in human tendon cultures, expressed as units/gram of tendon tissue. A: Subscapularis tendon sample from patient with tear. B: Subscapularis sample from same patient as in $A$, but taken from site removed from tear. $C$ : Supraspinatus tendon taken from area of attrition. D: Supraspinatus tendon from same patient as in $C$, but from an area of tendon of normal appearance close to the muscle. 
In general, the levels of TIMP exceeded those of collagenase throughout the assay period. Figure 1A illustrates the results obtained for a tendon sample taken from a degenerate portion of subscapularis tendon. TIMP levels are higher than the corresponding collagenase values; should the collagenase be activated in the culture supernatant, there appears to be sufficient TIMP to prevent activity. A similar picture of TIMP and collagenase secretion was found in a sample of tissue that appeared macroscopically normal taken from the same patient but away from the tear (fig 1B). Figure $1 \mathrm{C}$ and $\mathrm{D}$ illustrate the results obtained from tendon taken from another patient but in two different regions of the tendon: figure $1 \mathrm{C}$ shows low levels of TIMP produced by an area of central tendon (described as an area of attrition) where almost equimolar concentrations of collagenase and TIMP are produced, while figure 1D shows the levels of collagenase and TIMP produced from an area of tendon close to the muscle end where much higher levels of TIMP were produced. The greater amounts of TIMP produced by this latter tissue showed a large variability apparently caused by some tissue segments producing high levels of TIMP while others produced low levels. When all the results for TIMP and collagenase were compared, TIMP levels (mean 94.7 (66.8) U/g) were generally greater than those of collagenase (mean $32.9(48 \cdot 0) \mathrm{U} / \mathrm{g}$ ) (data not shown).

Only relatively few samples had greater amounts of collagenase than of TIMP; in figure 2 , these are the eight samples to the left of the line representing the molar equivalence point for TIMP and collagenase. Interestingly, several of these samples were from a single patient with calcific tendinitis; figure 3 illustrates the time course of changes in the levels of collagenase and TIMP measured in the culture supernatants taken from this patient. When the levels of collagenase and TIMP measured in the day 3 supernatants were compared for all the tendon samples, divided into 'normal' tendon, and diseased/'abnormal' tendon, both TIMP and collagenase were present in greater amounts in the normal tendon samples (fig 4): mean values for TIMP

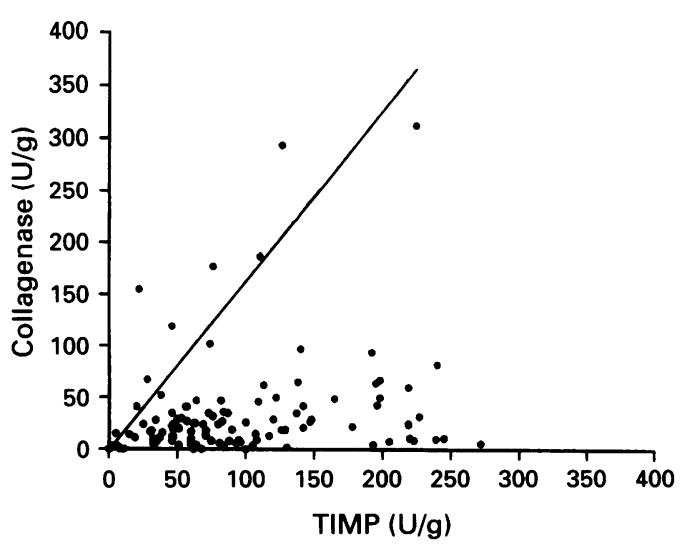

Figure 2 Comparison of the levels of collagenase and tissue inhibitor of metalloproteinases (TIMP) in human tendon culture medium, expressed as units/gram wet weight of tendon tissue. The line shows the molar equivalence point of collagenase and TIMP.

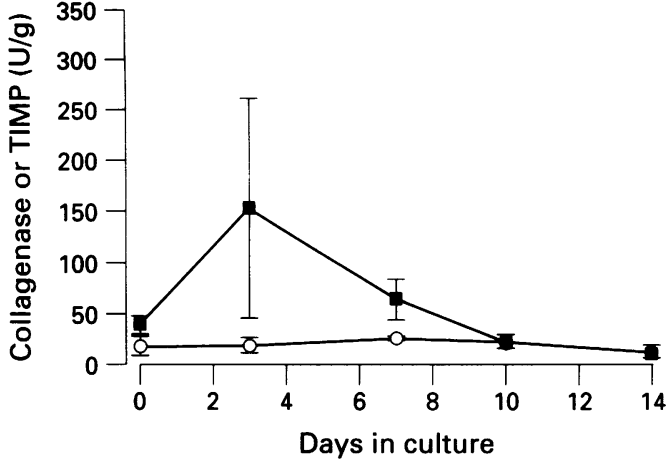

Figure 3 Levels of collagenase ( $\square$ ) and tissue inhibitor of metalloproteinases (TIMP) (O) in human tendon culture media from a calcific tendon, expressed as units/gram of tendon tissue.

were $109 \cdot 7(62 \cdot 3) \mathrm{U} / \mathrm{g}$ in normal tissue and $53.0(27.9) \mathrm{U} / \mathrm{g}$ in diseased tissue $(\mathrm{p}<0.05)$; corresponding figures for collagenase were $95.2(106.8) \mathrm{U} / \mathrm{g}$ in normal tissue and 34.0 $(45 \cdot 3) \mathrm{U} / \mathrm{g}$ in diseased tendon (not significant).

The collagenolytic activity detected in the medium was confirmed as the metalloproteinase collagenase by the activation with trypsin, incubation with collagen, and separation by SDS-PAGE; the cleavage of collagen into $3 / 4$ and $1 / 4$ fragments was clearly seen (fig 5). The cleavage was inhibited by the metalloproteinase inhibitor 1.10-phenanthroline, which confirmed the presence of fibroblast collagenase (MMP-1). In addition, Western blotting of the unactivated medium by SDS-PAGE and transfer to nitrocellulose showed that the majority of the collagenase was in the procollagenase form $\left(M_{\mathrm{r}}-55000\right)$ and was detected at $M_{\mathrm{r}}-55000$, whilst a small amount of active collagenase was detected at $M_{\mathrm{r}}-45000$, confirming that the collagenolytic activity detected was attributable to the fibroblast collagenase (MMP-1) (fig 6).

\section{Discussion}

Although previous studies have examined the ability of tendon to repair after injury, 2568 very little work has been completed on human

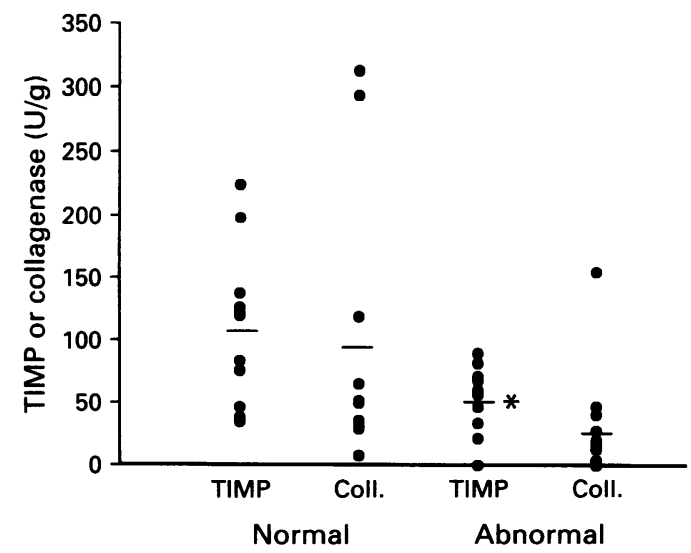

Figure 4 Comparison of the levels of collagenase and tissue inhibitor of metalloproteinases (TIMP) in the culture medium at day 3 of culture of normal and diseased human tendons, expressed as units/gram of tendon tissue.

Horizontal lines indicate mean values. ${ }^{*} p<0.05$ compared with normal tissue. 


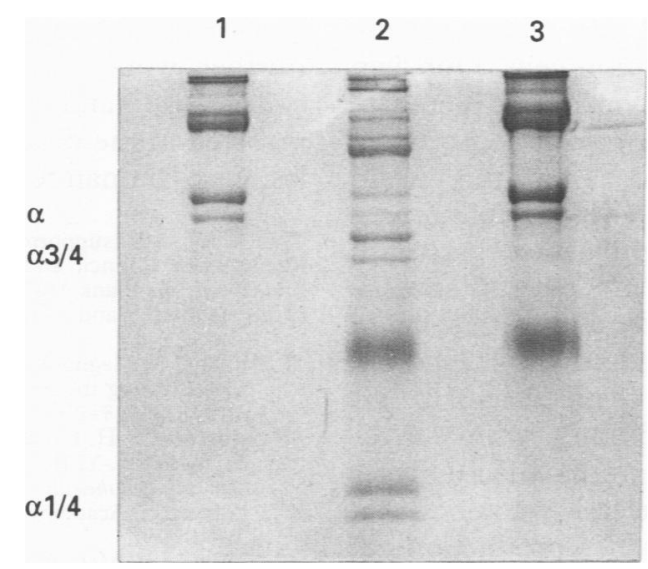

Figure 5 Cleavage of type I collagen by trypsin activated concentrated tendon explant culture medium containing high levels of collagenase (patient 15, day 6). SDS-PAGE separation and Coomassie Brilliant Blue staining. LANE $1=$ Collagen incubated with no enzyme present; LANE $2=$ collagen cleaved into $1 / 4$ and 3/4 fragments; LANE $3=$ cleavage inhibited by the metalloproteinase inhibitor, 1.10-phenanthroline.

tendon tissue, owing to the difficulty of obtaining biopsy specimens of human tendon. While some studies have examined the histological appearance of such samples, ${ }^{22-24}$ insufficient tissue has hitherto been available to complete the organ culture work described in the present report. In this study we have been able to collect, for the first time, a series of human diseased and normal tendon samples in sufficient quantity to examine their behaviour in tissue culture.

The mechanisms involved in the repair of tendon tissue are not well characterised. Some studies suggest that the cells in the epitenon proliferate after injury, migrate to the site of injury and are responsible for the repair process. ${ }^{8}$ The damaged collagen, removed by proteolysis, would then be replaced by new collagen molecules synthesised by the tendon cells and incorporated into the collagen fibres. As collagenase is the only proteinase that

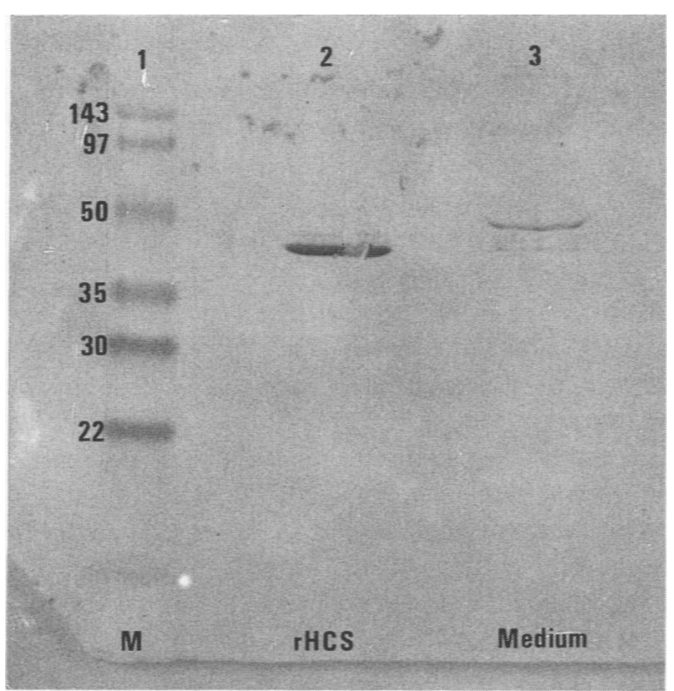

Figure 6 Western blotting of concentrated medium sample containing collagenase and TIMP (patient 15, day 6). LANE $1=\mathrm{M}$, markers $(M) ;$ LANE $2=$ recombinant human collagenase standard (rHCS); LANE $3=$ concentrated culture media from tendon explant culture. Both procollagenase and small amounts of active collagenase can be detected in the culture medium sample. specifically cleaves collagen to give $1 / 4-3 / 4$ products, it is likely that this enzyme is involved in this process. The synthesis of TIMP and collagenase identified in this study indicates that the tissue is able actively to repair and degrade collagen within the tissue before resynthesis of collagen.

In this study, most tendons produced a molar excess of TIMP compared with collagenase. Most of the collagenase was in a proenzyme form; that is, it would require activation before it could digest collagen. If all of the collagenase was activated, TIMP would still be present in excess in most of the media samples collected. However, other metalloproteinases may be present in the culture medium and, once activated, these additional enzymes could also bind TIMP, allowing connective tissue proteins to be degraded by active metalloproteinases when present in excess. The measurement of the biological activity of individual enzymes can therefore be misleading, and future work will characterise the culture medium to examine if gelatinases and stromelysins are present. An alternative to the biological assays are immunological assays which can measure the total amount of any enzyme or inhibitor present: thus measurement of TIMP would measure free TIMP (still biologically active), but would not distinguish it from TIMP complexed to any matrix metalloproteinases. The assays used in this study can give information on the ability of a tissue for collagen turnover, as they measured biological activity.

The division of the tendon samples into two groups was somewhat arbitrary. All the tendons collected in this series were removed at operations to remove diseased human tendon at a late stage of disease. However, some tissue appeared macroscopically normal upon removal and was distinct from macroscopically abnormal tissue removed from the immediate area of the tendon lesion. The results suggest that the abnormal tissue was less metabolically active, as the levels of both TIMP and collagenase produced by these tissues were reduced compared with the tissue described as normal. A probable explanation is that tissue close to the site of rupture has failed to repair and is consequently weaker, so rupture of the tissue occurs; some of the cells within the tissue close to the site of rupture then die, with the result that less protein is synthesised and secreted. Alternatively, it is possible that some of the abnormal tissue becomes more fibrous after damage and so contains fewer cells, which would account for the smaller amounts of collagenase and TIMP. Three portions of tissue from each tendon sample were cultured and, in some samples, markedly different levels of collagenase and TIMP release occurred, suggesting that a substantial variation occurs even within the same tissue.

It is of interest that increased amounts of collagenase were produced by a calcified tendon. Synovial cells are known to respond to crystals when added to culture, by increasing the levels of collagenase produced; ${ }^{25}$ further 
work will establish if this also occurs on the addition of calcium to tendon cells. Our own recent studies have shown that degenerate tendons with increased calcium contents had a reduced collagen content, ${ }^{11}$ and this could suggest that the increased levels of collagenase present had effected a significant degradation of the collagen. Archer $e t a l^{26}$ recently investigated human rotator cuff tendons with calcium deposits present. Many tendon samples showed rounded cells within the calcified matrix and these areas were also infiltrated with macrophages. It is possible that the macrophages produce collagenase or release cytokines that are able to stimulate the production of collagenase by resident connective tissue cells, leading to a reduction in collagen content in these tissues.

It is known that cells removed from aging human tendons can successfully be grown in culture, ${ }^{27}$ and preliminary results have shown that they can produce TIMP in cell culture and also respond to the addition of cytokines such as interleukin-1 by increasing the synthesis and secretion of collagenase ( $\mathrm{H}$ Bigg, in preparation). Work is in progress to study further the effects of various growth factors and cytokines on tendon fibroblasts in culture, to determine if they respond in the same way as other connective tissue fibroblasts.

Although this is the first report of the production of collagenase and TIMP by normal and diseased human tendon in organ culture, some previous work has described the production of TIMP by normal tendon samples. The first example of the purification of TIMP was reported by Vater et al after the culture of human tendon in organ culture. ${ }^{28}$ Large quantities of conditioned culture medium were obtained and the purified TIMP was shown to be identical with that produced by other tissues.

Previous studies have measured neutral metalloproteinases both in chick tendon tissue and by chick tendon cells in culture, and identified these at gelatinase-A (MMP-2) ${ }^{29}$ after zymography of concentrated culture medium. Harper et $a l^{30}$ cultured rabbit patellar tendon and suggested that the infrequent observation of collagenase activity before day 6 in culture may have been caused by the presence of inhibitory proteins, although these were not identified. Harper's group also cultured rabbit patellar tendon for 14 days and showed that normal tissue produced more active collagenase than tissue that had been immobilised for a period of four weeks. ${ }^{30} 31$ The immobilised tissue appeared to produce less collagenase protein than the normal tendon tissue. In a later study, these authors also examined the amount of collagenase inhibitor produced by the same rabbit tissues, ${ }^{32}$ and showed that there was no significant difference between the immobilised tissues and the control tissue in the changes in the levels of inhibitory activity produced.

This study has shown that human tendon tissue, even from late stage chronic lesions, is capable of producing the enzyme collagenase and its specific inhibitor TIMP that are involved in the control of collagen breakdown. Further work will establish to what extent collagenase and its inhibitor TIMP are involved in the destruction of collagen seen in lesions of human tendon in vivo.

This work was supported in part by the Arthritis and Rheumatis was supported in part by the Arthritis and Endeavour. We thank Mrs Sheila Smith for expert preparation of the manuscript and references.

1 Squier C A, Magnes C. Spatial relationships between fibroblasts during the growth of rat-tail tendon. Cell Tiss Res 1983; 234: 17-29.

2 Gelberman R H, Goldberg V, An K-N, Banes A. Tendon. In: Woo S L-Y, Buckwalter J A, eds. Injury and repair of the musculoskeletal soft tissues. Park Ridge, Illinois: American Academy of Orthopaedic Surgeons, 1988; $1-40$.

3 Williams I F, McCullagh K G, Silver I A. The distribution of types I and III collagen and fibronectin in the healing equine tendon. Conn Tiss Res 1984;12: 211-22.

4 Potenza A D. Critical evaluation of flexor-tendon healing and adhesion formation within artificial digital sheaths. f Bone foint Surg Am 1963; 45: 1217-33.

5 Manske P R, Gelberman R H, Vandeberg J S, Lesker P A Intrinsic flexor tendon repair: a morphological study in vitro. F Bone foint Surg Am 1984; 66: 385-96.

6 Lundborg G, Rank F. Experimental intrinsic healing of flexor tendons based upon synovial fluid nutrition. 7 Hand Surg 1978; 3: 21-31.

7 Becker H, Graham M F, Cohen I K, Diegelmann R F. Intrinsic tendon cell proliferation in tissue culture. $\mathcal{F}$ Hand Surg 1981; 6: 616-9.

8 Duffy F J, Seiler J G, Hergrueter C A, Kandel J, Gelberman R H. Intrinsic mitogenic potential of canine Gelberman R H. Intrinsic mitogenic potentia

9 Russell J E, Manske P R. Collagen synthesis during primary flexor tendon repair in vitro. $\mathcal{F}$ Orthop Res 1990; 8: 13-20.

10 Abrahamsson S-O. Matrix metabolism and healing in the flexor tendon. Experimental studies on rabbit tendon. Scand f Plast Reconstr Surg Hand Surg 1991; 23 (25 suppl): $1-51$.

11 Riley G P, Harrall R L, Constant C R, Chard M D, Cawston T E, Hazleman B L. Tendon degeneration and chronic shoulder pain: changes in the collagen composition of the human rotator cuff tendons in rotator cuff tendinitis. Ann Rheum Dis 1994; 53: 359-66.

12 Riley G P, Harrall R L, Constant C R, Chard M D, Cawston T E, Hazleman B L. Glycosaminoglycans of human rotator cuff tendons: changes with age and in chronic rotator cuff tendinitis. Ann Rheum Dis 1994; 53 367-76.

13 Laurent G J. Dynamic state of collagen: pathways of collagen degradation in vivo and their possible role in regulation of collagen mass. Am 7 Physiol 1987; 252: Ci-9.

14 Woessner J F. Matrix metalloproteinases and their inhibitors in connective tissue remodelling. FASEB $\mathcal{f} 1991$; 5: 2145-54.

15 Gross J, Lapierre C M. Collagenolytic activity in amphibian tissues: a tissue culture assay. Proc Natl Acad $S c i U S A$ 1962; 54: 1197-204.

16 Cawston T E, Murphy G, Mercer E, et al. The interaction of purified rabbit bone collagenase with purified rabbit bone metalloproteinase inhibitor. Biochem $\mathcal{f} 1983 ; 211$ 313-8.

17 Birkedal-Hansen H, Moore W G I, Bodden M K, et al. Matrix metalloproteinases: A review. Crit Rev Oral Biol Med 1993; 4: 197-250.

18 Cawston T E, Barrett A J. A rapid and reproducible assay for collagenase using (1-14C) acetylated collagen. Anal Biochem 1979; 99: 340-5.

19 Clark I M, Powell E K, Wright J K, Cawston T E, Hazleman B L. Monoclonal antibodies against human fibroblast collagenase and the design of an enzyme linked fibroblast collagenase and the design of an enzyme linked immunosorbent

20 Clark I M, Powell E K, Wright J K, Cawston T E. Polyclonal and monoclonal antibodies against human tissue inhibitor of metalloproteinases (TIMP) and the design of an enzyme linked immunosorbent assay to measure TIMP. Matrix 1991; 11: 76-85.

21 Andrews H J, Plumpton T A, Harper G P, Cawston T E. A synthetic peptide metalloproteinase inhibitor, but not TIMP, prevents the breakdown of proteoglycan within articular cartilage. Agents Actions 1992; 37: 147-54.

22 Yamanaka $\mathrm{K}$, Fukuda H. Ageing process of the supraspinatus tendon with reference to rotator cuff tears. In: Edinburgh: Churchill Livingston, 1991; 247-50.

23 Kannus P, Jozsa L. Histopathological changes preceeding spontaneous rupture of a tendon. $\mathcal{f}$ Bone foint Surg Am 1991; 73: 1507-25.

24 Chard M D, Cawston T E, Riley G P, Gresham G A, Hazleman B L. Rotator cuff degeneration and lateral Hazleman B L. Rotator cuff degeneration and latera epichonylitis: a comparative

25 Cheung H S, Halverson P B, McCarty D J. Release of collagenase, neutral protease, and prostaglandins from cultured mammalian synovial cells by hydroxyapatite and 
calcium pyrophosphate dihydrate crystals. Arthritis Rheum 1981; 24: 1338-44

26 Archer R S, Bayley J I L, Archer C W, Ali S Y. Cell and matrix changes associated with pathological calcification of the human rotator cuff tendons. F Anat 1993; 182: 1-12.

27 Chard M D, Wright J K, Hazleman B L. Isolation and growth characteristics of adult human tendon fibroblasts. Ann Rheum Dis 1987; 46: 385-90.

28 Vater C A, Mainardi C L, Harris E D. Inhibitor of human collagenase from cultures of human tendon. $\mathcal{f} \mathrm{Biol}$ Chem 1979; 254: 3045-53.
29 Piening C, Reiderer-Henderson M A. Neutral metalloproteinases from tendons. $\mathcal{F}$ Orthop Res $1989 ; 7: 228-34$.

30 Harper J, Amiel D, Harper E. Collagenase production by rabbit ligaments and tendon. Conn Tiss Res 1988; 17: 253-9.

31 Harper J, Amiel D, Harper E. Collagenase from periarticular ligaments and tendon: Enzyme levels during periarticular ligaments and tendon: Enzyme levels durin 200-5. $200-5$

32 Harper J, Amiel D, Harper E. Inhibitors of collagenase in ligaments and tendons of rabbits immobilised for 4 weeks. Conn Tiss Res 1992; 28: 257-61. 